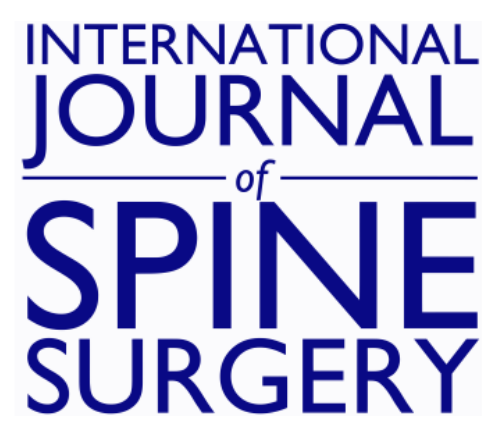

\title{
Combined Depression and Anxiety Influence Patient-Reported Outcomes after Lumbar Fusion
}

Dhruv K.C. Goyal, Justin D. Stull, Srikanth N. Divi, Matthew S. Galetta, Daniel R. Bowles, Kristen J. Nicholson, I. David Kaye, Barrett I. Woods, Mark F. Kurd, Kris E. Radcliff, Jeffrey A. Rihn, D. Greg Anderson, Alan S. Hilibrand, Christopher K. Kepler, Alexander R. Vaccaro and Gregory D. Schroeder

Int J Spine Surg 2021, 15 (2) 234-242

doi: https://doi.org/10.14444/8008

http://ijssurgery.com/content/15/2/234

This information is current as of April 25, 2023.

Email Alerts Receive free email-alerts when new articles cite this article. Sign up at: http://ijssurgery.com/alerts 


\title{
Combined Depression and Anxiety Influence Patient- Reported Outcomes after Lumbar Fusion
}

\author{
DHRUV K.C. GOYAL, MD, JUSTIN D. STULL, MD, SRIKANTH N. DIVI, MD, MATTHEW S. GALETTA, BA, \\ DANIEL R. BOWLES, MD, KRISTEN J. NICHOLSON, PHD, I. DAVID KAYE, MD, BARRETT I. WOODS, \\ MD, MARK F. KURD, MD, KRIS E. RADCLIFF, MD, JEFFREY A. RIHN, MD, D. GREG ANDERSON, MD, \\ ALAN S. HILIBRAND, MD, CHRISTOPHER K. KEPLER, MD, MBA, ALEXANDER R. VACCARO, MD, \\ PHD, MBA, GREGORY D. SCHROEDER, MD \\ Department of Orthopaedic Surgery, Rothman Institute, Thomas Jefferson University, Philadelphia, Pennsylvania
}

\begin{abstract}
Background: Currently, no studies have assessed what effect the presence of both anxiety and depression may have on patient-reported outcome measurements (PROMs) compared to patients with a single or no mental health diagnosis.

Methods: Patients undergoing 1- to 3-level lumbar fusion at a single academic hospital were retrospectively queried. Anyone with depression and/or anxiety was identified using an existing clinical diagnosis in the medical chart. Patients were separated into 3 groups: no depression or anxiety (NDA), depression or anxiety alone (DOA), and combined depression and anxiety (DAA). Absolute PROMs, recovery ratios, and the percentage of patients achieving minimal clinically important difference (\% MCID) between groups were compared using univariate and multivariate analysis.

Results: Of the 391 patients included in the cohort, $323(82.6 \%)$ were in the NDA group, $37(9.5 \%)$ in the DOA group, and $31(7.9 \%)$ in the DAA group. Patients in the DAA group had significantly worse outcome scores before and after surgery with respect to Short Form-12 mental component score (MCS-12) and Oswestry Disability Index (ODI) scores $(P<.001)$; however, the change in PROMs, recovery ratio, \% MCID were not found to be significantly different between groups. Using multivariate analysis, the DAA group was found to be an independent predictor of worse improvement in MCS-12 and ODI scores $(P=.026$ and $P=.001$, respectively).

Conclusions: Patients with combined anxiety and depression fared worse with respect to disability before and after surgery compared to patients with a single diagnosis or no mental health diagnosis; however, there were no significant differences in recovery ratio or \% MCID.
\end{abstract}

Level of Evidence: 3.

Clinical Relevance: Combined anxiety and depression may predict less improvement in MCS-12 and ODI after lumbar arthrodesis compared with single or no mental health diagnosis.

Lumbar Spine

Keywords: PROMs, HRQOL outcome scales, SF-12, PCS-12, MCS-12, ODI, VAS back, VAS leg, depression, anxiety, mental health, lumbar, arthrodesis, fusion

\section{INTRODUCTION}

Lumbar fusion is a commonly performed surgery to address symptomatic spinal stenosis with concomitant instability. Over the past decade, the rate of lumbar fusions has been steadily increasing, with almost 200000 surgeries performed annually. ${ }^{1}$ Elective lumbar fusion for degenerative disease, specifically for spondylolisthesis, has been reported to result in higher patient-satisfaction scores and improved patient-reported outcome measurements (PROMs). ${ }^{2-6}$ Many risk factors have been identified that ultimately affect patient outcomes following fusion; however, preoperative mental health comorbidities including anxiety and depression, have been associated with higher rates of complications and worse patient outcomes. ${ }^{7-10}$

There is growing interest in PROMs in spine literature; as such, it is important to understand how these metrics may be translated into improved patient care. While PROMs may be used to objectively determine the effectiveness of a surgical intervention, further work must be done to understand how these metrics change in the presence of baseline risk factors. Currently, there is conflicting evidence as to whether preoperative mental health 
comorbidities lead to worse outcomes following lumbar surgery. ${ }^{11-18}$ Even more poorly defined is how these baseline conditions affect PROMs after surgical intervention for degenerative lumbar disease. Given increasing attention towards outcomesbased care in spine surgery, the purpose of this study was to determine if, and to what extent, patients with a preoperative diagnosis of depression and/or anxiety demonstrate worse outcomes after lumbar fusion.

\section{METHODS}

\section{Patient Selection and Data Collection}

This study was approved by the Institutional Review Board at the Thomas Jefferson University Hospital. Each author certifies that his or her institution approved the human protocol for this investigation and that all investigations were conducted in conformity with ethical principles of research. After gaining approval from the Institutional Review Board, a retrospective cohort study was initiated on patients who received lumbar fusion surgery from one of several orthopedic spine surgeons at a single high-volume center between January 1, 2013, and December 31, 2017. Patientsincluding those with spondylolisthesis, scoliosis, recurrent disc herniation, or lumbar spinal stenosis - underwent either posterolateral fusion alone or combined posterolateral fusion with anterior lumbar interbody fusion or transforaminal lumbar interbody fusion to address a variety of degenerative lumbar conditions. Anyone under 18 years of age and those who demonstrated under 1 year of clinical follow-up were excluded from the final cohort; furthermore, individuals who received surgical intervention to address malignancy, infection, trauma, or revision of a prior lumbar surgery were also left out of the final sample.

A standard set of demographic data and surgical characteristics was collected and recorded for each patient from the institution's electronic health record system (eCW V11, eClinicalWorks, Westborough, Massachusetts), including age, sex, body mass index (BMI), smoking status (never, current, former), preoperative diagnosis, total number of levels decompressed, total number of levels fused, months of clinical follow-up, and duration of symptoms prior to surgical intervention $(<3$ months, 3-6 months, $>6$ months). Baseline and postoperative (1-year) PROMs-including the
Short Form-12 physical component score (PCS-12) and mental component score (MCS-12), the Oswestry Disability Index (ODI), and the Visual Analogue Scale back (VAS back) and leg (VAS leg) pain scores - were obtained through a structured query language search in the institution's PROM tracking software (OBERD, Columbia, MO). Each outcome was measured at baseline and the 1-year postoperative mark.

Electronic health records and office notes were then reviewed to assess whether a mental health diagnosis was present prior to surgery. Subsequently, patients were split into 1 of 3 groups based on the presence of any officially documented diagnosis of depression and/or anxiety in their records: (1) no depression or anxiety (NDA) group; (2) depression or anxiety (DOA) group; and (3) depression and anxiety (DAA) group. In a secondary analysis, patients in the DOA group were split into depression-only (DO) and anxiety-only (AO) groups.

\section{Statistical Analysis}

Data were assessed for normality of distribution using measures of skewness and kurtosis, and the Shapiro-Wilk test. Demographics and surgical data were compared between the 3 groups. Each set of PROMs was assessed for changes from baseline to postoperative measurement within groups using paired samples $t$ test. Outcomes were then compared between groups for differences in preoperative, postoperative, and delta (postoperative minus preoperative) scores. Categorical variables were compared using Pearson $\chi^{2}$ analysis or Fisher exact test, and continuous variables were compared using 1way ANOVA or Kruskal-Wallis $\mathrm{H}$ test with Bonferroni and Dunn multiple pairwise comparison testing, respectively, for post-hoc analysis. Two additional measures of improvement were calculated and compared between groups: recovery ratios (RR) and the percentage of patients who ended up achieving the minimum clinically important difference ( $\%$ MCID) at final follow-up. RR was defined as delta score/(optimal score - baseline score), where 100 was used as an optimal score for PCS12 and MCS-12 and a score of 0 was optimal for ODI, VAS back, and VAS leg. ${ }^{19}$ The \% MCID calculated for each PROM was based on the following threshold values: PCS-12, 8.8 points; MCS-12, 9.3 points; ODI, 6.8 points; VAS back, 2.1 points; and VAS leg, 2.4 points. $^{20,21}$ Finally, a set of multiple linear regression analyses was 
Table 1. Descriptive statistics of cohort by mental health diagnosis groups. Descriptive characteristics between groups are compared via Kruskal-Wallis $\mathrm{H}$ test, Pearson $\chi^{2}$ analysis, or Fisher exact test.

\begin{tabular}{|c|c|c|c|c|}
\hline & $\begin{array}{l}\text { No Depression or Anxiety } \\
(\mathrm{n}=323)\end{array}$ & $\begin{array}{c}\text { Depression or Anxiety } \\
(\mathbf{n}=37)\end{array}$ & $\begin{array}{c}\text { Depression and Anxiety } \\
(\mathrm{n}=31)\end{array}$ & $P$ Value \\
\hline Age, mean $(95 \% \mathrm{CI}), \mathrm{y}$ & $63.0(61.0,64.0)$ & $62.0(58.0,66.0)$ & $61.0(58.0,64.0)$ & .809 \\
\hline Sex, n $(\%)$ & & & & .057 \\
\hline M & $168(52.0)$ & $21(56.8)$ & $23(74.2)$ & \\
\hline $\mathrm{F}$ & $155(48.0)$ & $16(43.2)$ & $8(25.8)$ & \\
\hline Body mass index, $\mathrm{kg} / \mathrm{m}^{2}(95 \% \mathrm{CI})$ & $30.4(29.8,31.1)$ & $30.6(29.1,32.1)$ & $30.7(28.7,32.8)$ & .962 \\
\hline Smoking status, $\mathrm{n}(\%)$ & & & & $.001^{\mathrm{a}}$ \\
\hline Never & $228(70.6)$ & $20(54.1)$ & $16(51.6)$ & \\
\hline Current & $22(6.8)$ & $1(2.7)$ & 7 (22.6) & \\
\hline Former & $73(22.6)$ & $16(43.2)$ & $8(25.8)$ & \\
\hline Preoperative diagnosis, $\mathrm{n}(\%)$ & & & & .723 \\
\hline Spondylolisthesis & $228(70.6)$ & $23(62.2)$ & $21(67.8)$ & \\
\hline Scoliosis & $43(13.3)$ & $5(13.5)$ & $5(16.1)$ & \\
\hline Recurrent disc herniation & $11(3.4)$ & $1(2.7)$ & $0(0.0)$ & \\
\hline Stenosis & $41(12.7)$ & $8(21.6)$ & $5(16.1)$ & \\
\hline No. of levels decompressed, n (\%) & & & & .750 \\
\hline 1 & $140(43.3)$ & $21(56.8)$ & $11(35.5)$ & \\
\hline 2 & $103(31.9)$ & $7(18.9)$ & $12(38.7)$ & \\
\hline 3 & $61(18.9)$ & 7 (18.9) & $6(19.4)$ & \\
\hline 4 & $16(5.0)$ & $2(5.4)$ & $2(6.4)$ & \\
\hline 5 & $3(0.9)$ & $0(0.0)$ & $0(0.0)$ & \\
\hline No. of levels fused, n (\%) & & & & 279 \\
\hline 1 & $224(69.3)$ & $31(83.8)$ & $20(64.5)$ & \\
\hline 2 & $78(24.1)$ & $6(16.2)$ & $8(25.8)$ & \\
\hline 3 & $21(6.6)$ & $0(0.0)$ & $3(9.7)$ & \\
\hline Follow-up, mean $(95 \% \mathrm{CI})$, mo & $13.6(13.0,14.1)$ & $13.4(12.4,14.4)$ & $13.3(11.6,15.1)$ & .953 \\
\hline Symptom duration, $\mathrm{n}(\%)$ & & & & .338 \\
\hline$<3 \mathrm{mo}$ & $238(73.7)$ & $28(75.7)$ & $19(61.3)$ & \\
\hline 3-6 mo & $50(15.5)$ & $4(10.8)$ & $9(29.0)$ & \\
\hline$>6 \mathrm{mo}$ & $35(10.8)$ & $5(13.5)$ & $3(9.7)$ & \\
\hline
\end{tabular}

${ }^{\mathrm{a}}$ Indicates statistical significance $(P<.05)$.

performed to determine whether preoperative mental health diagnoses were predictors of worse outcomes after lumbar fusion surgery. Each regression was conducted using the NDA group as a baseline for comparison and controlled for age, sex, BMI, smoking status, preoperative diagnosis, number of levels decompressed, number of levels fused, months of clinical follow-up, and duration of symptoms prior to surgery. Statistical analysis was also repeated by splitting the DOA group into DO and AO groups in the secondary analysis. All statistical analyses were performed using the SPSS version 24 (IBM Corporation, Armonk, NY). A $P$ value less than .05 was considered to be statistically significant.

\section{RESULTS}

\section{Patient Demographics}

A total 391 patients were included in the final set of analysis, with $323(82.6 \%)$ in the NDA group, 37 $(9.5 \%)$ in the DOA group, and $31(7.9 \%)$ in the DAA group. The average age of patients in the overall cohort was 62 (95\% confidence interval [CI]: $61,64)$ years, mean BMI was 30.5 (95\% CI: 29.9,
31.1 ), and total number of male participants was $212(54.2 \%)$. There were 264 never $(67.5 \%), 30$ current $(7.7 \%)$, and 97 former $(24.8 \%)$ smokers in this set of patients, $272(69.6 \%)$ of which underwent surgical intervention to address spondylolisthesis, $53(18.2 \%)$ for scoliosis, $12(3.1 \%)$ for recurrent nucleus pulposus herniation, and $54(9.1 \%)$ for stenosis. The average length of clinical follow-up was 13.5 months. In terms of surgical characteristics, $172(44.0 \%)$ patients received a 1-level decompression, $122(31.2 \%)$ a 2-level decompression, 74 $(18.9 \%)$ a 3 -level decompression, $20(5.1 \%)$ a 4-level decompression, and $3(0.8 \%)$ a 5-level decompression. A total of $275(70.3 \%)$ patients underwent a 1level fusion, $92(23.5 \%)$ a 2-level fusion, and 24 $(6.2 \%)$ a 3 -level fusion. Demographic data and surgical characteristics between groups in the primary analysis can be located in Table 1 .

\section{Patient-Reported Outcome Measurements}

All groups demonstrated significant improvement after surgery in every PROM domain $(P<.05)$, except that patients in the DOA group did not improve in terms of MCS-12 scores $(P=.225)$. When comparing baseline outcome scores between groups, 
the DAA group was found to exhibit worse disability than the NDA group in terms of MCS12 (42.3 versus 50.7, $P<.001$ ) and ODI scores (49.5 versus $40.0, P=.001)$. This trend was also observed for postoperative measurements, with the DAA group exhibiting significantly greater disability than the NDA group in terms of MCS-12 (47.3 versus $54.4, P<.001)$ and ODI (32.2 versus $19.9, P=.001)$. Neither delta scores, nor RRs, nor \% MCID were found to be significantly different between any of the groups. In spite of this finding, multiple linear regression analysis revealed that the having either depression or anxiety alone (DAA) group was a significant predictor of decreased improvement in MCS-12 ( $\beta$ coefficient: -4.016 [95\% CI: -7.551 , -0.480 ], $P=.026)$ and ODI $(\beta$ coefficient: 11.768 [95\% CI: 4.677, 18.858], $P=.001)$ scores over time compared to the NDA group. Outcome comparisons between groups for the primary analysis can be located in Table 2.

When conducting a secondary analysis by separating patients with depression alone (DO) or anxiety alone (AO), all groups again demonstrated significant improvement from baseline to postoperative measurements in all outcome measures except for the DO and $\mathrm{AO}$ groups - both of which failed to improve in terms of MCS-12 $(P=.132$ and $P=.877$, respectively). Comparing outcome scores between groups, the DAA still showed worse MCS-12 and ODI scores compared to the NDA group at baseline and postoperatively $(P<.05)$. Neither delta scores, nor RRs, nor \% MCID were found to be significantly different between groups. Multiple linear regression analysis again revealed that the DAA group was a significant predictor decreased improvement in MCS-12 ( $\beta$ coefficient: -3.988 [95\% CI: $-7.527,-0.450], P=.027)$ and ODI $(\beta$ coefficient: 11.767 [95\% CI: 4.665, 18.869], $P=$ .001) scores over time, when using the NDA group as a baseline for comparison. Results of the secondary analysis are detailed in Table 3.

\section{DISCUSSION}

The purpose of this study was to determine if, and to what extent, having preoperative depression and/or anxiety influences PROMs in patients who require lumbar fusion surgery to address degenerative lumbar disease. The results of the current study found that patients with combined depression and anxiety prior to lumbar fusion had worse pain and disability than patients who no prior mental health comorbidities in terms of MCS-12 and ODI scores $(P<.001)$ both preoperatively and postoperatively. While the groups did not demonstrate any significant differences in the various measures of improvement including delta scores, recovery ratios, and \% MCID for any PROMs in the analysis, multiple linear regression analyses indicated that having both combined depression and anxiety prior to surgery was a significant predictor of worse improvement in MCS-12 $(P=.027)$ and ODI $(P=$ $.001)$, compared to having no baseline mental health diagnoses. These trends were also found in the secondary analysis.

Interestingly, patients having a single mental health diagnosis (DO or AO groups) did not improve with respect to MCS-12 scores, whereas patients with both (DAA) did improve. However, this may be related to the fact that MCS-12 represents the global mental functioning of a patient. Hence, patients with more baseline mental health dysfunction are likely to continue to experience this dysfunction after surgery. MCS-12 scores are closely related to the presence of depression and a few studies have attempted to define thresholds. $^{22-24}$

Current literature shows examining the impact of preoperative mental health and outcomes following lumbar arthrodesis shows conflicting reports. Several studies have associated anxiety and/or depression with less satisfaction and improvement, and worse health-related quality of life scores, after lumbar fusion when compared to patients with no preoperative mental health comorbidities. However, there are others that report opposite or neutral findings in this particular domain. ${ }^{1-18}$ In one retrospective comparative study in patients that underwent instrumented lumbar decompression and fusion surgery for recurrent stenosis, patients with depression-identified by preoperative Zung selfrating depression score - were found to have significantly greater dissatisfaction scores 2 years after surgery (odds ratio $=0.67$ [95\% CI: 0.38, 0.87], $P<$ $.001) .^{10}$ In a separate study, 231 patients who underwent lumbar fusion for any reason were retrospectively reviewed. The authors of this study found that a worse baseline EuroQOL-5 Dimensions score or a clinical diagnosis of depression, determined by the Patient Health Questionnaire-9, was associated with a significantly greater chance of not achieving MCID at 1 year of clinical follow-up $(P<.05) .{ }^{11}$ Similarly, in a retrospective study by 


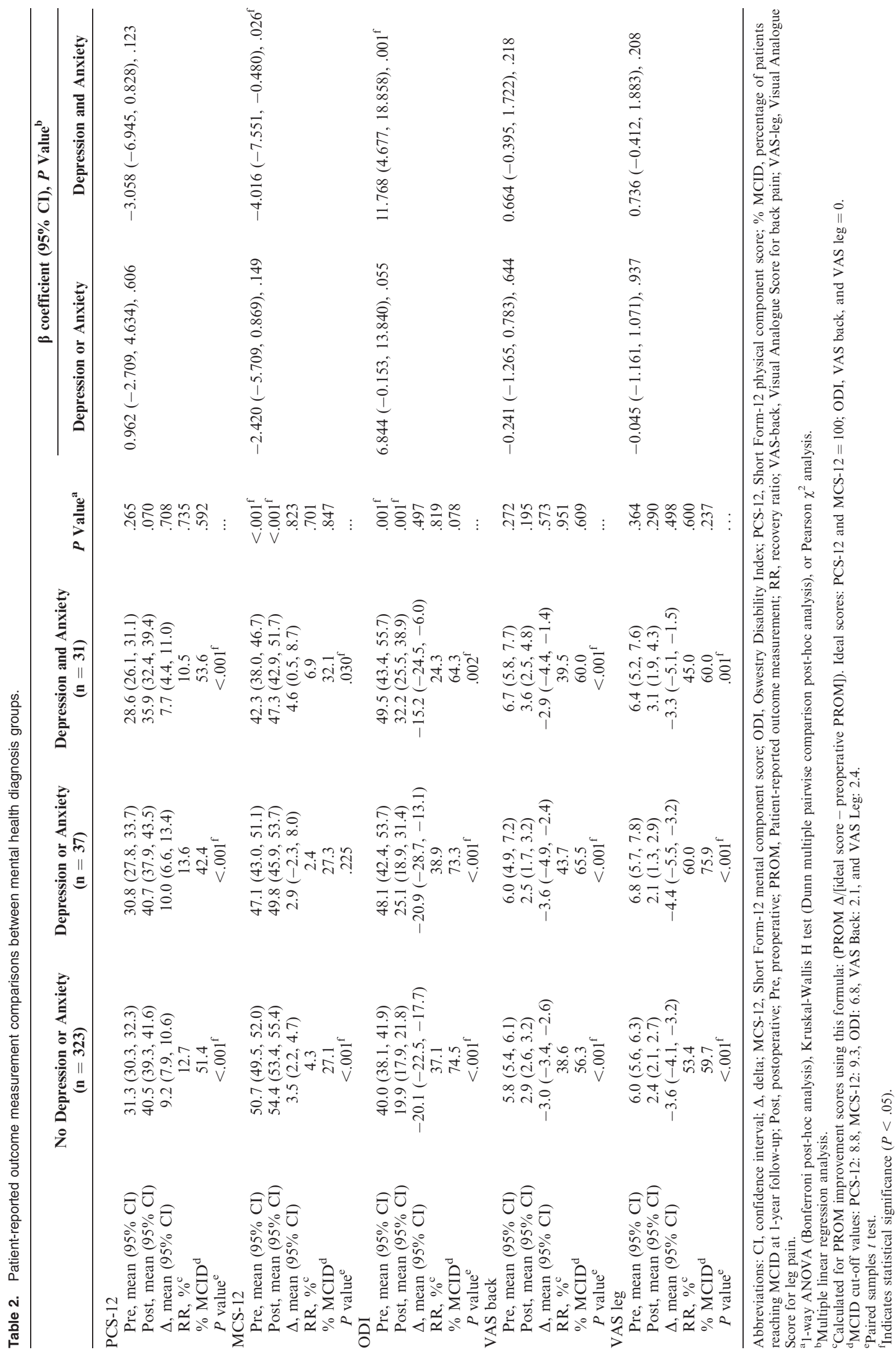


Goyal et al.

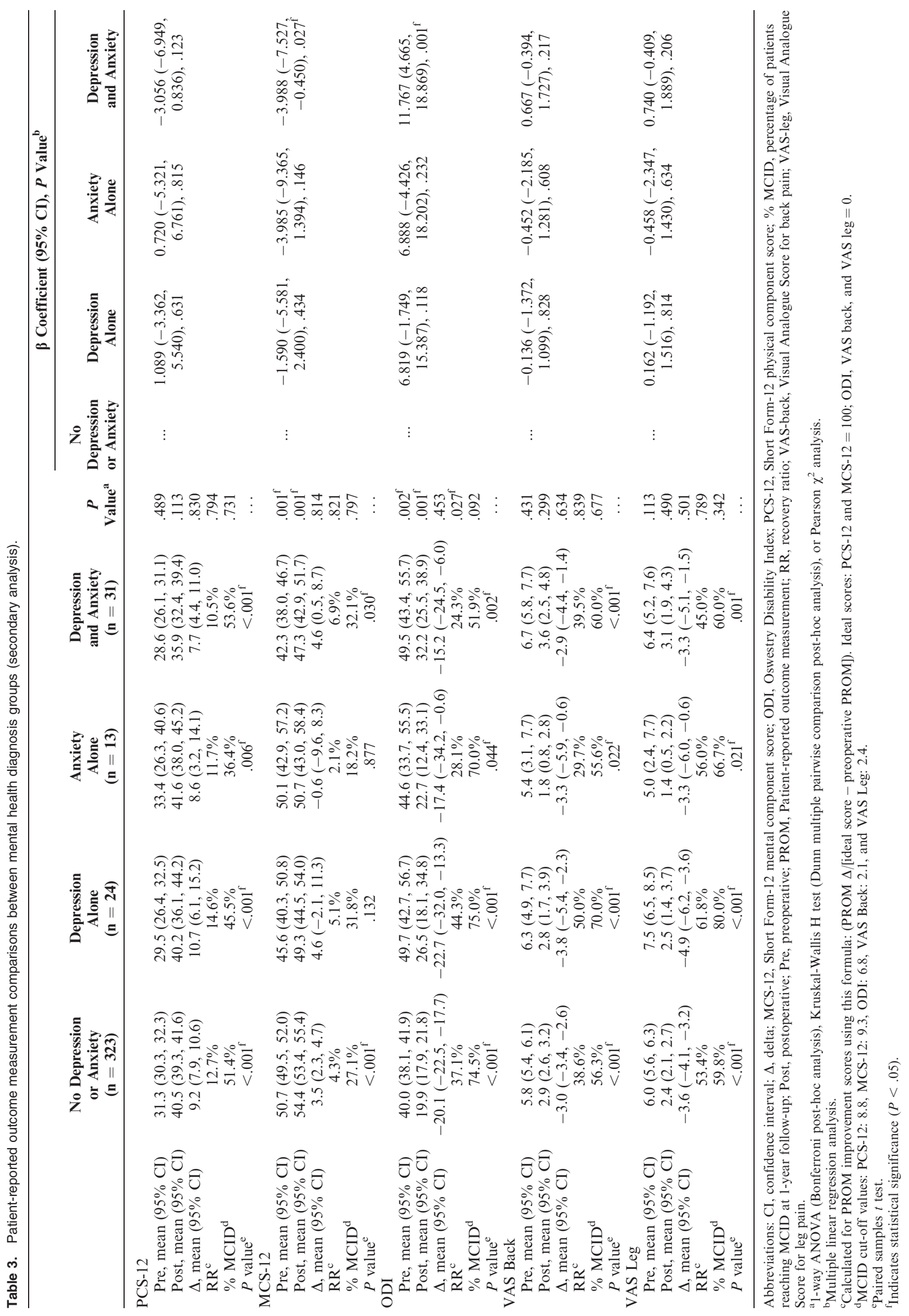


Wahlman et $\mathrm{al}^{16}$ examining 232 patients who underwent lumbar fusion, patients with preoperative symptoms of depression-identified by the Depression Scale - were found to have significantly less disability in terms of ODI at the 3-month and 1year clinical follow-up visits $(P<.001)$. The findings of these studies suggest that having preexisting depression seems to lead to worse outcomes even when using a variety of different measures. One plausible explanation between depression and outcomes is that they are inextricably linked because of the presence of chronic pain. ${ }^{25-28}$

While the aforementioned studies have focused on depression alone as an independent risk factor for worse outcomes after lumbar fusion surgery, other studies have considered the influence of anxiety on outcomes. In a retrospective study by Lee et al, ${ }^{15}$ patients with depression or anxiety were identified using Hospital Anxiety and Depression Scale (HADS), noting that depression and anxiety were each significantly correlated with worse disability in terms of ODI scores $(r=-0.054$ and $r=$ -0.276 , respectively, $P<.001)$ but not VAS scores. In another study by Carreon et $\mathrm{al},{ }^{28}$ patients' subjective feeling of being downhearted or depressed was a significant predictor of worse ODI scores after lumbar fusion. However, the same study indicated that a preoperative diagnosis of depression or anxiety did not significantly predict worse outcomes after arthrodesis. Finally, a prospective trial by Netto et $a 1^{17}$ revealed that patients with depression or anxiety, identified by the HADS scale, were found to have significantly greater pain scores $(P<.001)$, but the same level of physical functioning and improvement in ODI scores. The different results in the abovementioned studies may be attributed to unstandardized methods as well as instruments used. The results of the present study indicate that depression or anxiety alone were not associated with worse PROM improvement after lumbar fusion; however, combined depression and anxiety was associated with greater disability in terms of ODI scores. There are no other studies to date which have examined the impact that combined depression and anxiety have on patient-reported outcomes following lumbar fusion. This suggests that it may be important to consider anxiety in combination with depression when assessing the influence of mental health on PROMs.

There are several limitations to the current study including the fact the patients who were identified as having anxiety or depression through the medical chart were not verified by a validated outcome scale (ie HADS), but rather were rather listed as officially having one of these diagnoses at any point prior to surgery. This may have resulted in classifying patients who had a remote a history of major depressive disorder or generalized anxiety disorder who may have already received adequate treatment prior to surgery; hence, their preoperative mental health diagnosis may not be as accurate as originally anticipated. Furthermore, this would imply that patients with the mental health conditions who have never been formally diagnosed could also have been classified as having no depression and/or anxiety in spite of potentially subclinical baseline mental health symptoms. Incorrect classification of groups may have also resulted in the imbalanced sample sizes used for primary comparison (DOA: $n=37$; DAA: $n=31$ ), potentially weakening the findings of this study. Finally, the severity of the diagnoses was not determined, which would have helped further elucidate the impact of increasingly severe composite mental health states on PROMs after lumbar arthrodesis. With all of this in mind, the major limitations ascribed above are all related by the retrospective nature of the study, as certain details would have been better determined with appropriate prospective planning. Any studies that plan to further elucidate the relationship between mental health and PROMs after lumbar fusion should attempt to do so in a prospective manner; ultimately, this would result in more accurate baseline mental health diagnoses and thorough stratification of symptom severity at preoperative evaluations.

\section{CONCLUSION}

Patients with combined depression and anxiety were found to have significantly worse baseline and postoperative ODI scores compared to the subset of patients with no mental health comorbidities prior to surgery. Furthermore, having combined depression and anxiety was predictive of less improvement in terms of ODI scores. This is the first study to incorporate combined depression and anxiety as a risk factor for worse outcomes after lumbar fusion. More studies must be conducted to further elucidate this association.

\section{REFERENCES}

1. Martin BI, Mirza SK, Spina N, Spiker WR, Lawrence B, Brodke DS. Trends in lumbar fusion procedure rates and 
associated hospital costs for degenerative spinal diseases in the United States, 2004 to 2015. Spine. 2019;44(5):369-376. doi:10. 1097/BRS.0000000000002822

2. Veresciagina K, Mehrkens A, Schären S, Jeanneret B. Minimum ten-year follow-up of spinal stenosis with degenerative spondylolisthesis treated with decompression and dynamic stabilization. J Spine Surg. 2018;4(1):93-101. doi:10.21037/jss. 2018.03.20

3. Schaeren S, Broger I, Jeanneret B. Minimum four-year follow-up of spinal stenosis with degenerative spondylolisthesis treated with decompression and dynamic stabilization. Spine. 2008;33(18):E636-642. doi:10.1097/BRS.0b013e31817d2435

4. Weinstein JN, Lurie JD, Tosteson TD, et al. Surgical versus nonsurgical treatment for lumbar degenerative spondylolisthesis. N Engl J Med. 2007;356(22):2257-2270. doi:10.1056/ NEJMoa070302

5. Weinstein JN, Lurie JD, Tosteson TD, et al. Surgical compared with nonoperative treatment for lumbar degenerative spondylolisthesis. Four-year results in the Spine Patient Outcomes Research Trial (SPORT) randomized and observational cohorts. J Bone Joint Surg Am. 2009;91(6):1295-1304. doi:10.2106/JBJS.H.00913

6. Sun W, Xue C, Tang X-Y, et al. Selective versus multisegmental decompression and fusion for multi-segment lumbar spinal stenosis with single-segment degenerative spondylolisthesis. J Orthop Surg. 2019;14(1):46. doi:10.1186/s13018-0191092-2

7. O'Connell C, Azad TD, Mittal V, et al. Preoperative depression, lumbar fusion, and opioid use: an assessment of postoperative prescription, quality, and economic outcomes. Neurosurg Focus. 2018;44(1):E5. doi:10.3171/2017.10. FOCUS17563

8. Derby R, Lettice JJ, Kula TA, Lee S-H, Seo K-S, Kim BJ. Single-level lumbar fusion in chronic discogenic low-back pain: psychological and emotional status as a predictor of outcome measured using the 36-item Short Form. J Neurosurg Spine. 2005;3(4):255-261. doi:10.3171/spi.2005.3.4.0255

9. Schoell K, Wang C, D'Oro A, et al. Depression increases the rates of neurological complications and failed back surgery syndrome in patients undergoing lumbar spine surgery. Clin Spine Surg. 2019;32(2):E78. doi:10.1097/BSD. 0000000000000730

10. Adogwa O, Carr K, Fatemi P, et al. Psychosocial factors and surgical outcomes: are elderly depressed patients less satisfied with surgery? Spine. 2014;39(19):1614-1619. doi:10. 1097/BRS.0000000000000474

11. Alentado VJ, Caldwell S, Gould HP, Steinmetz MP, Benzel EC, Mroz TE. Independent predictors of a clinically significant improvement after lumbar fusion surgery. Spine $J$. 2017;17(2):236-243. doi:10.1016/j.spinee.2016.09.011

12. Miller JA, Derakhshan A, Lubelski D, et al. The impact of preoperative depression on quality of life outcomes after lumbar surgery. Spine J. 2015;15(1):58-64. doi:10.1016/j.spinee. 2014.06.020

13. Merrill RK, Zebala LP, Peters C, Qureshi SA, McAnany SJ. Impact of depression on patient-reported outcome measures after lumbar spine decompression. Spine. 2018;43(6):434-439. doi:10.1097/BRS.0000000000002329

14. Høy K, Bünger C, Niederman B, et al. Transforaminal lumbar interbody fusion (TLIF) versus posterolateral instrumented fusion (PLF) in degenerative lumbar disorders: a randomized clinical trial with 2-year follow-up. Eur Spine J. 2013;22(9):2022-2029. doi:10.1007/s00586-013-2760-2

15. Lee J, Kim H-S, Shim K-D, Park Y-S. The effect of anxiety, depression, and optimism on postoperative satisfaction and clinical outcomes in lumbar spinal stenosis and degenerative spondylolisthesis patients: cohort study. Clin Orthop Surg. 2017;9(2):177-183. doi:10.4055/cios.2017.9.2.177

16. Wahlman M, Häkkinen A, Dekker J, Marttinen I, Vihtonen K, Neva MH. The prevalence of depressive symptoms before and after surgery and its association with disability in patients undergoing lumbar spinal fusion. Eur Spine $J$. 2014;23(1):129-134. doi:10.1007/s00586-013-2896-0

17. Netto MB, Barranco ABS, Oliveira KWK de, Petronilho F. Influence of anxiety and depression symptoms on the quality of life in patients undergoing lumbar spine surgery. Rev Bras Ortop. 2017;53(1):38-44. doi:10.1016/j.rboe.2017.01.009

18. Abbott AD, Tyni-Lenné R, Hedlund R. The influence of psychological factors on pre-operative levels of pain intensity, disability and health-related quality of life in lumbar spinal fusion surgery patients. Physiotherapy. 2010;96(3):213-221. doi:10.1016/j.physio.2009.11.013

19. Radcliff K, Davis RJ, Hisey MS, et al. Long-term evaluation of cervical disc arthroplasty with the Mobi-C(C) cervical disc: a randomized, prospective, multicenter clinical trial with seven-year follow-up. Int J Spine Surg. 2017;11:31. doi: $10.14444 / 4031$

20. Parker SL, Mendenhall SK, Shau DN, et al. Minimum clinically important difference in pain, disability, and quality of life after neural decompression and fusion for same-level recurrent lumbar stenosis: understanding clinical versus statistical significance. J Neurosurg Spine. 2012;16(5):471-478. doi:10.3171/2012.1.SPINE11842

21. Parker SL, Adogwa O, Paul AR, et al. Utility of minimum clinically important difference in assessing pain, disability, and health state after transforaminal lumbar interbody fusion for degenerative lumbar spondylolisthesis. $J$ Neurosurg Spine. 2011;14(5):598-604. doi:10.3171/2010.12. SPINE10472

22. Gill SC, Butterworth P, Rodgers B, Mackinnon A. Validity of the mental health component scale of the 12-item Short-Form Health Survey (MCS-12) as measure of common mental disorders in the general population. Psychiatry Res. 2007;152(1):63-71. doi:10.1016/j.psychres.2006.11.005

23. Walsh TL, Homa K, Hanscom B, Lurie J, Sepulveda MG, Abdu W. Screening for depressive symptoms in patients with chronic spinal pain using the SF-36 health survey. Spine $J$. 2006;6(3):316-320. doi:10.1016/j.spinee.2005.11.004

24. Gornet MF, Copay AG, Schranck FW, Kopjar B. observational study of depression in patients undergoing cervical disc arthroplasty: evidence of a correlation between pain relief and resolution of depression. Int J Spine Surg. 2016;10:11. doi:10.14444/3011

25. Bair MJ, Wu J, Damush TM, Sutherland JM, Kroenke K. Association of depression and anxiety alone and in combination with chronic musculoskeletal pain in primary care patients. Psychosom Med. 2008;70(8):890-897. doi:10.1097/ PSY.0b013e $318185 \mathrm{c} 510$

26. McWilliams LA, Cox BJ, Enns MW. Mood and anxiety disorders associated with chronic pain: an examination in a nationally representative sample. Pain. 2003;106(1-2):127-133. doi:10.1016/s0304-3959(03)00301-4

27. Scott KM, Bruffaerts R, Tsang A, et al. Depression- 
anxiety relationships with chronic physical conditions: results from the World Mental Health Surveys. J Affect Disord. 2007;103(1-3):113-120. doi:10.1016/j.jad.2007.01.015

28. Carreon LY, Djurasovic M, Dimar JR, et al. Can the anxiety domain of EQ-5D and mental health items from SF-36 help predict outcomes after surgery for lumbar degenerative disorders? J Neurosurg Spine. 2016;25(3):352-356. doi:10.3171/ 2016.2.SPINE151472

Disclosures and COI: The authors, their immediate families, and any research foundation with which they are affiliated did not receive any financial payments or other benefits from any commercial entity related to the subject of this article. There are no relevant disclosures.
Corresponding Author: Dhruv K.C. Goyal, MD, Department of Orthopaedic Surgery, Rothman Orthopaedic Institute, 925 Chestnut Street, Floor 5, Philadelphia PA, 19107. Phone: (937) 8307110; Email: dhruvkcgoyal@gmail.com.

Published 16 April 2021

This manuscript is generously published free of charge by ISASS, the International Society for the Advancement of Spine Surgery. Copyright $\odot 2021$ ISASS. To see more or order reprints or permissions, see http://ijssurgery.com. 